Research Article

\title{
Wideband Circularly Polarized Ellipse Antenna Array with Gain Enhancement
}

\author{
Li Wang $(\mathbb{D}$, Chang-liang Zhao, Rui Zhang, Xi Chen $(\mathbb{D}$, Guang Fu $(\mathbb{D}$, and Xiao-wei Shi
}

Science and Technology on Antenna and Microwave Laboratory, Xidian University, Xi'an, Shaanxi 710071, China

Correspondence should be addressed to Guang Fu; gfu@mail.xidian.edu.cn

Received 11 May 2018; Revised 24 July 2018; Accepted 12 August 2018; Published 17 September 2018

Academic Editor: Flaminio Ferrara

Copyright @ $2018 \mathrm{Li}$ Wang et al. This is an open access article distributed under the Creative Commons Attribution License, which permits unrestricted use, distribution, and reproduction in any medium, provided the original work is properly cited.

\begin{abstract}
In this paper, a wideband circularly polarized (CP) antenna element and array with gain enhancement are presented. The original antenna element adopts two orthogonal ellipse dipoles with end-loading pillars. In order to achieve a wide impedance bandwidth (IBW), a harpoon-shaped feed patch (HSFP) as electromagnetic coupling-feed is utilized. By introducing a coupled frame and a loop cavity, the gain of the element is crucially improved. Then, four sequentially rotated elements placed in a circular contour act as $2 \times 2$ array, and a similar loop metal cavity is employed to the array to reach gain enhancement. For the wideband CP performance of the proposed antenna, a wideband phase shifting feed network (WPSFN) is used to construct the antenna. Finally, to verify the feasibility of the proposed antenna, a prototype array is manufactured and measured. Experimental results are found in acceptable agreement with the simulated ones in terms of gain, radiation efficiency, radiation pattern, reflection coefficient, and axial ratio (AR). The result indicates that the proposed antenna has an IBW for reflection coefficient $\left|\mathrm{S}_{11}\right| \leq-10 \mathrm{~dB}$ of $85.7 \%(0.80-2.00 \mathrm{GHz})$. Moreover, benefit from the sequentially rotated technique (SRT), the AR at broadside direction keeps blow $3 \mathrm{~dB}$ during the overlapped bandwidth of $\left|\mathrm{S}_{11}\right| \leq-10 \mathrm{~dB}$, and the ARBW for $\mathrm{AR} \leq 1 \mathrm{~dB}$ of $74.4 \%$ $(0.85-1.78 \mathrm{GHz})$ can be achieved. By employing the loop cavity, the right hand circularly polarization (RHCP) gain is significantly improved, which keeps above $10.00 \mathrm{dBic}$ from $1.05 \mathrm{GHz}$ to $1.85 \mathrm{GHz}$, and the peak gain reaches to $13.91 \mathrm{dBic}$.
\end{abstract}

\section{Introduction}

Nowadays, with the rapid development of modern wireless communication system, CP antennas with advantages of anti-multi-path, better mobility, less polarization loss, and higher weather penetration have been widely used in various systems, such as compass navigation system (CNSS), global positioning system (GPS), radio frequency identification system, and local area network. With the trend of highspeed transmission and high data rate communication in wireless systems, CP antennas with wide bandwidth have received considerable attention. Thus, a few approaches for wideband $\mathrm{CP}$ antenna designs have been investigated. One of the efficiency methods to obtain broadband performance is the application of multiple-layer and stacked structures [1-4]. Such as [2], four rotated stacked patches were adopted to an aperture antenna to reach wideband $\mathrm{CP}$ radiation with $\mathrm{AR} \leq 3 \mathrm{~dB}$ within the band of 7.9-9.3 GHz. Nevertheless, this multiple-layer and stacked structure lead to difficulty of integrating with the equipment and high cost. Several types of CP slot antennas for improving bandwidth have been reported [5-7]. In [5], an antenna with a spidron fractal slot and an added rectangular slit on the ground was studied to enhance the AR bandwidth. As discussed in [7], by loading a lightning-shaped slot, a dual-broad CP bandwidth of $13.3 \%$ and $16.9 \%$ was reached. Unfortunately, all this kind of antenna have several drawbacks, such as bidirectional radiation and deformed radiation pattern. Furthermore, bandwidth can also be improved by utilizing wideband dipoles. As such, various crossed dipoles which were fed by self-phase shifting (SPS) structure were investigated on account of the wideband CP property [8-13]. As reported in [8], by employing an artificial magnetic conductor (AMC) with the SPS crossed dipole antennas, a $3 \mathrm{~dB}$ ARBW of $29.6 \%$ was obtained. Meanwhile, it has been demonstrated in [11] that a crossed dipole antenna with parasitic element could achieve a wide $3 \mathrm{~dB}$ ARBW of $63.4 \%$. Most of this kind of antennas show broad IBW and ARBW, whereas they suffer 


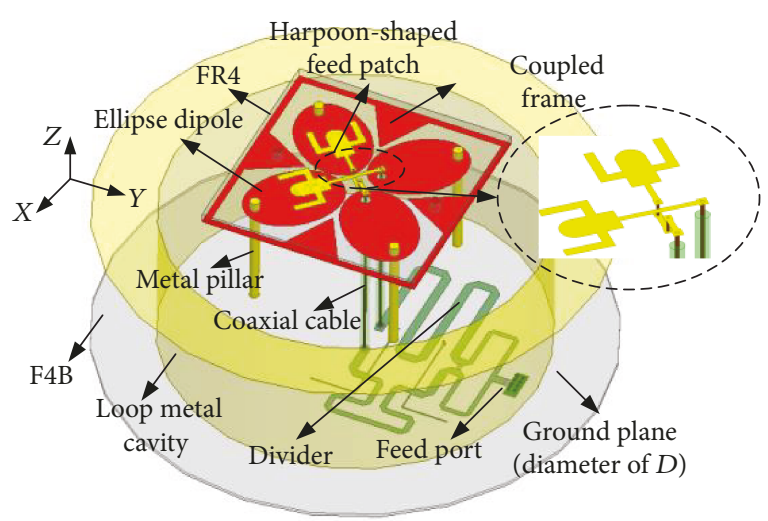

(a)

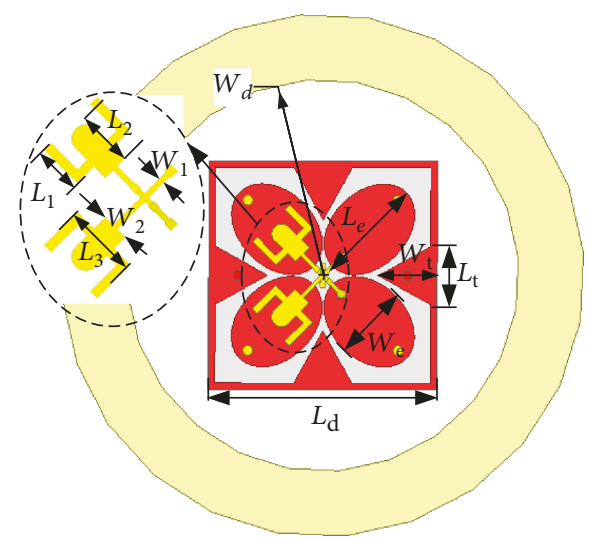

(c)

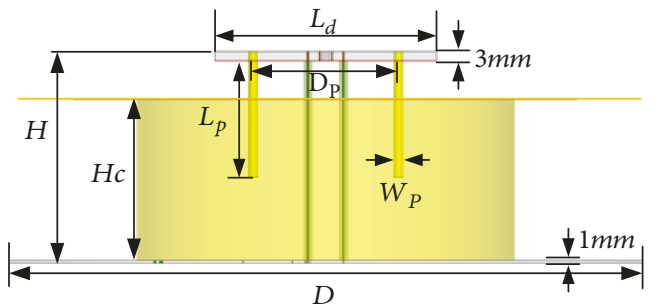

(b)

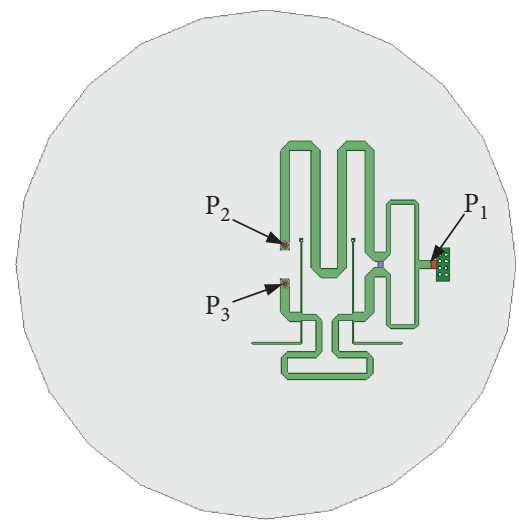

(d)

Figure 1: Geometry of the proposed antenna. (a) 3D view. (b) Side view. (c) Top view. (d) Element feed network.

crucial shortcomings of deformed radiation pattern and low cross polarization. Apart from the wide operating bandwidth, $\mathrm{CP}$ antennas with high gain are preferred. Especially in the GNSS, such properties ensure enough communication distance. To obtain a high gain performance, a modified horned reflector was employed to a double-layer folded electric dipole [14]. Antenna with Fabry-Perot cavity is another efficiency way to improve the gain $[15,16]$. Due to the limited band operating, such antennas cannot be adopted in wideband applications. In recent years, sequential rotation technique [17-21] for arrays has been discussed to improve the gain, bandwidth, and polarization purity. For example, the sequential rotation arrays (SRA) without ground planes were employed in [20] and exhibited a 120\% $3 \mathrm{~dB}$ ARBW. However, the 4-element SRA suffered from bidirectional radiation and poor gain (below $9 \mathrm{dBic}$ ). A noncoplanar corporate-fed $4 \times 4$ antenna array constructed from sequentially rotated $2 \times 2$ subarrays was presented in [18], and the proposed array obtained a $1 \mathrm{~dB}$ ARBW of $47.8 \%$. However, all the antenna elements or arrays, which are discussed above, cannot satisfy wideband performance, stable radiation pattern, and high gain at the same time.

In this paper, a novel concept to design wideband $\mathrm{CP}$ antenna with gain enhancement is presented. The antenna element consists of two wideband crossed ellipse dipoles (CED), two harpoon-shaped feed patches (HSFP), four end-loading pillars, a coupled frame, and a broadband phase shifting network. Compared with traditional dipoles, the ellipse dipoles with harpoon-shaped feed show excellent impedance and AR performance. Moreover, the loop cavity is employed to enhance the gain. Then, a $2 \times 2$ antenna array is proposed, which is composed of $2 \times 2$ ellipse elements, a broadband phase shifting network, and a loop cavity. Based on the SRT, the AR performance of the array has been further enhanced. Meanwhile, the gain of array is significantly enhanced by adopting a loop cavity. Finally, a prototype of the proposed antenna array has been fabricated and tested. Measurements were carried out to verify the simulations, and the measured results indicate good agreement with the simulated ones. All the investigation and results reveal that this antenna can be a good candidate for various navigation systems.

\section{Wideband Antenna Element}

2.1. Configuration of CP Antenna Element. Figure 1 shows the configuration proposed for a wideband CP antenna with gain enhancement. The configuration includes four parts: upper radiator, a feeding network, a loop metal cavity, and two coaxial cables. For maintaining band width of the proposed antenna, a FR4 $\left(\varepsilon_{r}=4.4, \tan \delta=0.002\right)$ with thickness of $3 \mathrm{~mm}$ is utilized for the upper substrate. As shown in the figure, two ellipse dipoles and coupled frame which are drawn by the red color as major radiators are printed on 


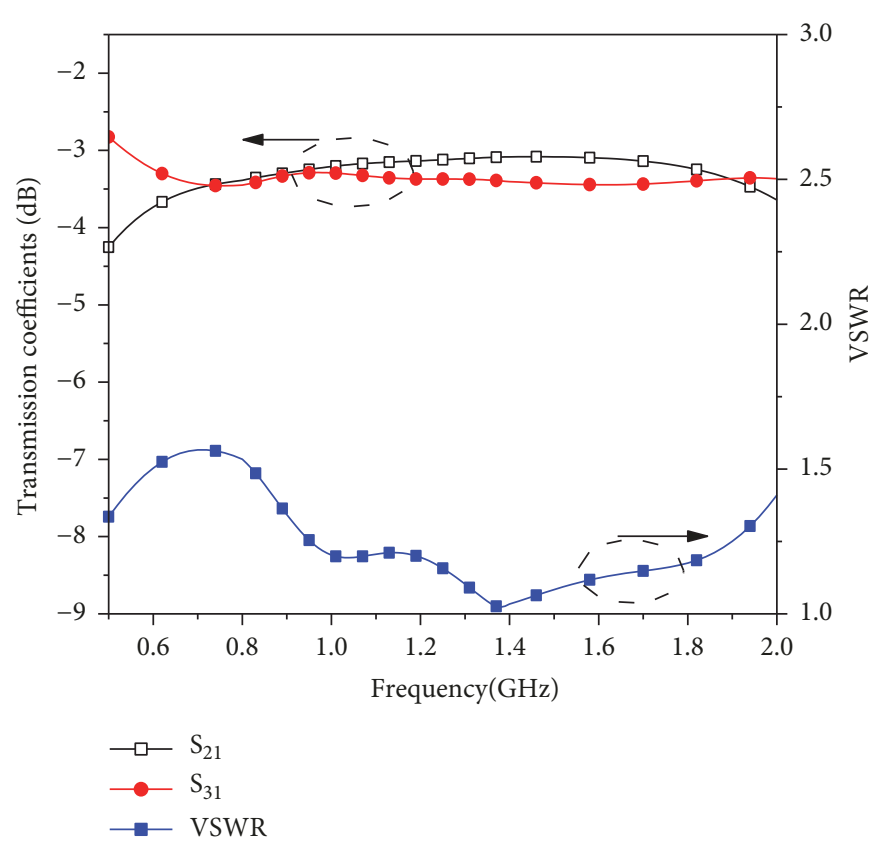

(a)

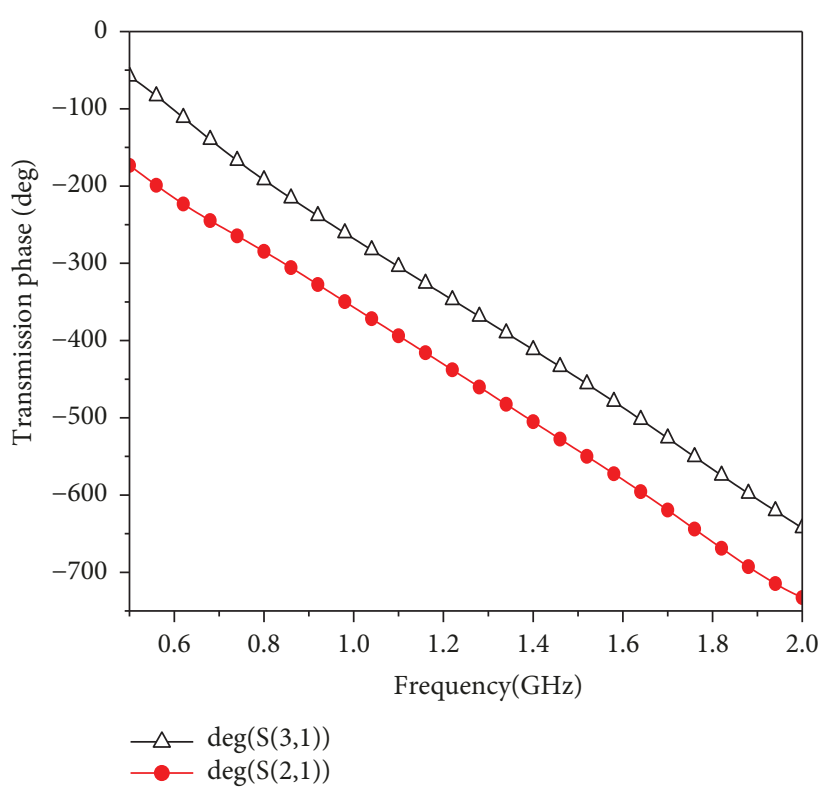

(b)

Figure 2: Performance of feed network. (a) Transmission coefficients and VSWR. (b) Transmission phases.

the bottom side of the upper PCB. Ellipse arms are all characterized by a major axis length $L_{\mathrm{e}}$ and a minor axis length $W_{\mathrm{e}}$, while the end of each arm loads a metal pillar with length of $L_{p}$ and diameter of $W_{p}$ to extend the current path. The length of the coupled frame is defined as $L_{d}$. Meanwhile, the height and side length of the triangle of the coupled frame are $L_{t}$ and $W_{p}$, respectively. On the top side of upper $\mathrm{PCB}$, the yellow parts are two HSFPs which are placed orthogonally to enhance the impedance bandwidth, and the specific parameters about the upper PCB are depicted in Figures 1(b) and 1(c). The width of feedline and middle part of the HSFP are decided by parameters $W_{1}$ and $W_{2}$, respectively. The side length and width of strip of the HSFP are labeled as $L_{1}$ and $L_{3}$. It can be seen that the HSFPs and the feeding network are connected by the inner conductors of coaxial cables. Meanwhile, the outer conductors are soldered on the ellipse arm. The length of coaxial cable is about $0.25 \lambda$ of $1.45 \mathrm{GHz}$. In order to improve the gain, a loop metal cavity which is the light yellow part with radius of $W_{d}$ and height of $H_{c}$ is around the antenna. By appropriately tuning the $W_{d}$ and $H_{c}$, high gain, wide ARBW, and IBW can be realized.

To make sure the bandwidth of antenna will be dominated by radiation part, a Wilkinson power divider with a modified Schiffman phase shifter [22] is provided and $\lambda_{\mathrm{g}} / 8$ open and short lines are adopted to tune the phase variation ( $\lambda_{\mathrm{g}}$ is the guided wavelength in the substrate). The structure shown in Figure 1(d) is the WPSFN on the bottom side of the lower PCB $\left(1 \mathrm{~mm}, \varepsilon_{\mathrm{r}}=2.65, \tan \delta=0.001\right)$, while the ground as a reflector is printed on the opposite side. The simulated performances of the network are shown in Figure 2, and the results illustrate that the operating band of $0.5-2 \mathrm{GHz}$ for $\mathrm{VSWR} \leq 1.50$ is obtained. The good

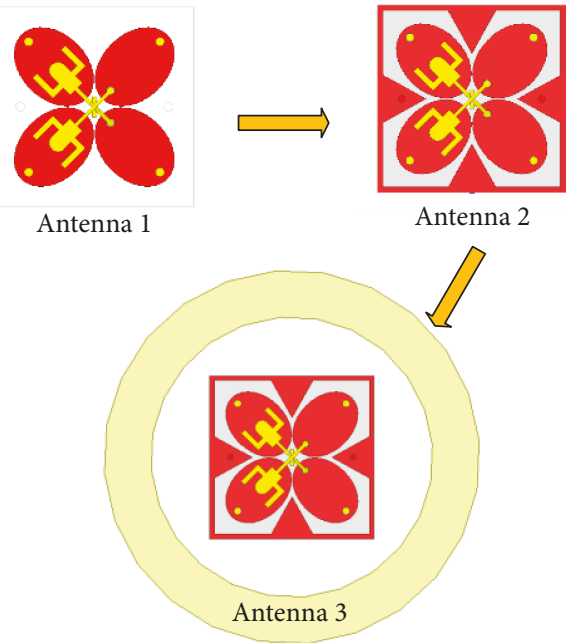

FIGURE 3: The design process of the proposed antenna.

transmission coefficients and phases ensure an equal magnitude and $90^{\circ}$ difference in the phase of each port.

\subsection{Design Process of the Proposed CP Antenna Element.} According to the order of applied techniques, the processes and comparisons are given as below. As shown in Figure 3, three types of models are deeply investigated to understand the influence of the techniques adopted to the proposed antennas. And three models are simulated by HFSS 13.0. The results of three antennas are listed in Figure 4. Meanwhile, the curves of the Antenna 1, Antenna 2, and Antenna 3 are marked in black, blue, and red color, respectively. Initially, ellipse dipoles with coupled fed reach a wide IBW for $\left|S_{11}\right| \leq-10 \mathrm{~dB}$ of $75.9 \%(0.80-1.78 \mathrm{GHz})$ and ARBW for 


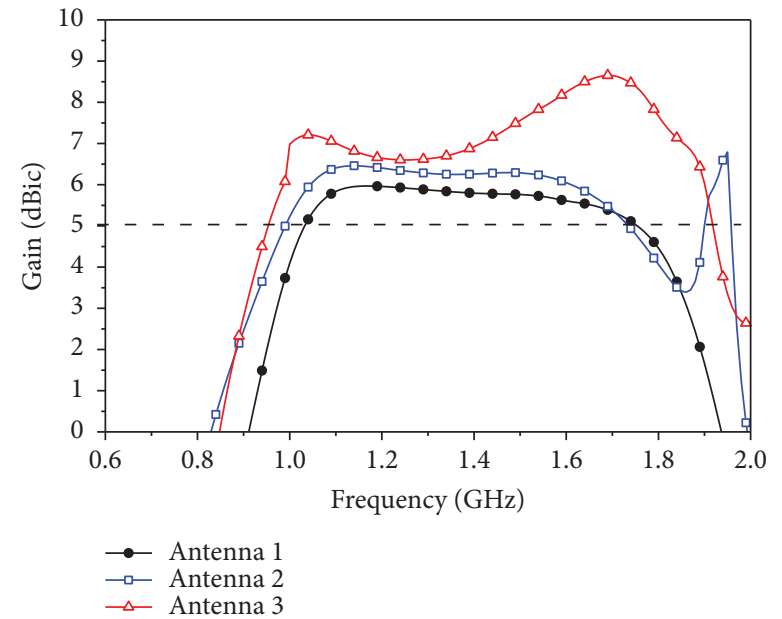

(a)

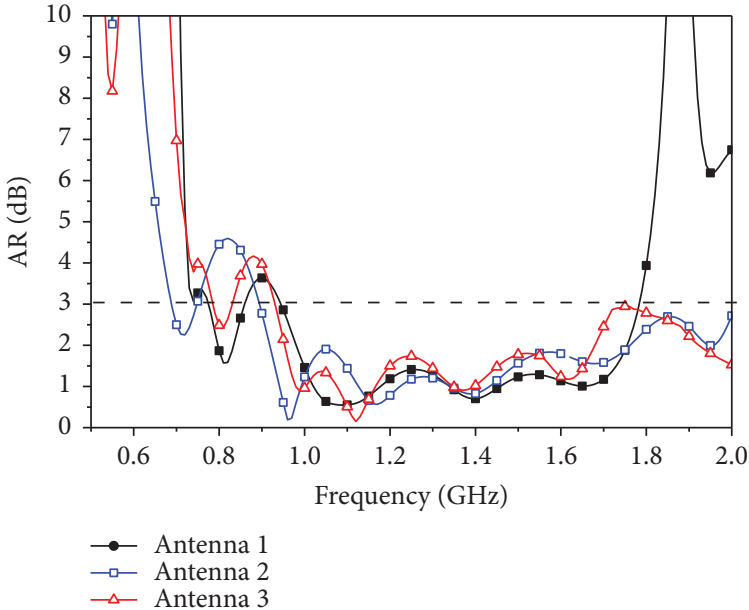

(b)

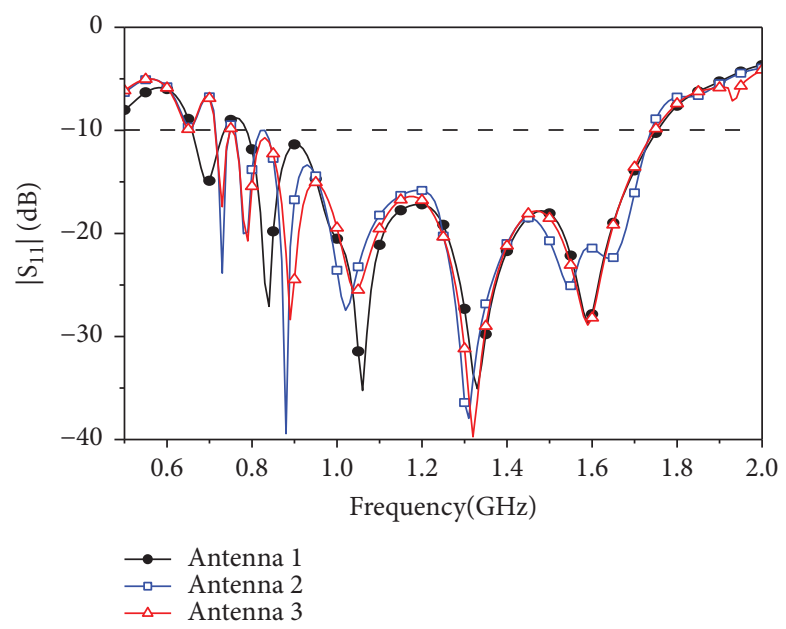

(c)

Figure 4: Comparison of ARs, gains at broadside direction, and $\left|S_{11}\right| s$ for three type of antennas.

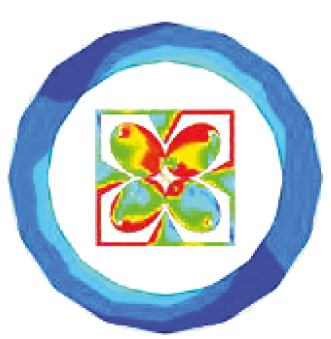

(a)

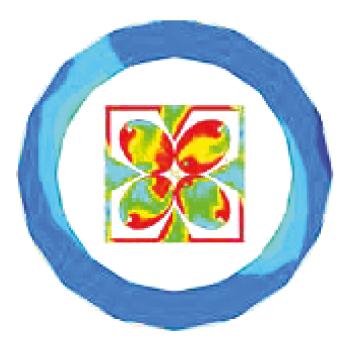

(b)

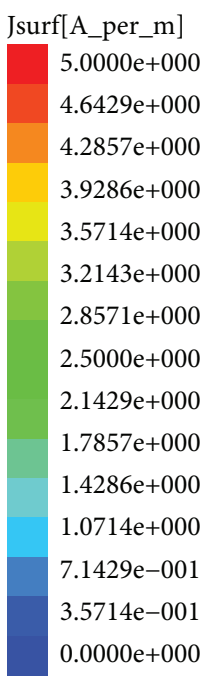

(c)

FIGURE 5: Simulated current distributions at (a) $1.0 \mathrm{GHz}$, (b) $1.4 \mathrm{GHz}$, and (c) $1.8 \mathrm{GHz}$. 

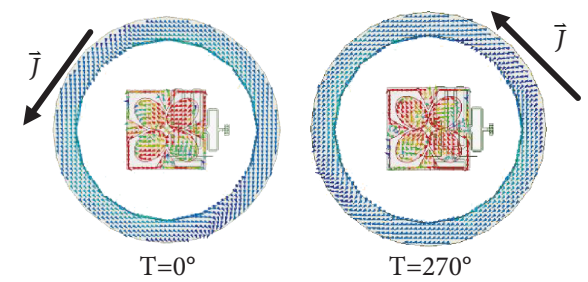

Jsurf[A_per_m]

$2.0000 \mathrm{e}+000$

$1.8574 \mathrm{e}+000$

$1.7149 \mathrm{e}+000$

$1.5723 \mathrm{e}+000$

$1.4298 \mathrm{e}+000$

$1.2872 \mathrm{e}+000$

$1.1447 \mathrm{e}+000$
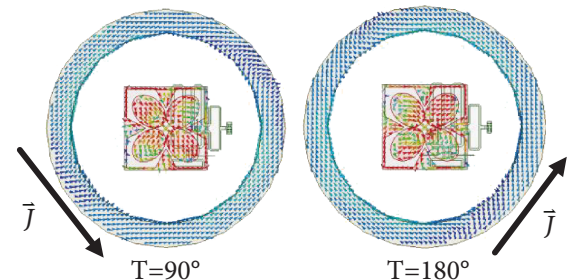

$8.5958 \mathrm{e}-001$

$7.1703 \mathrm{e}-001$

$5.7447 \mathrm{e}-001$

$4.3192 \mathrm{e}-001$

$2.8937 \mathrm{e}-001$

$1.4681 \mathrm{e}-001$

$4.2616 \mathrm{e}-003$

FIGURE 6: Current distribution at $1.4 \mathrm{GHz}$ with time instant.

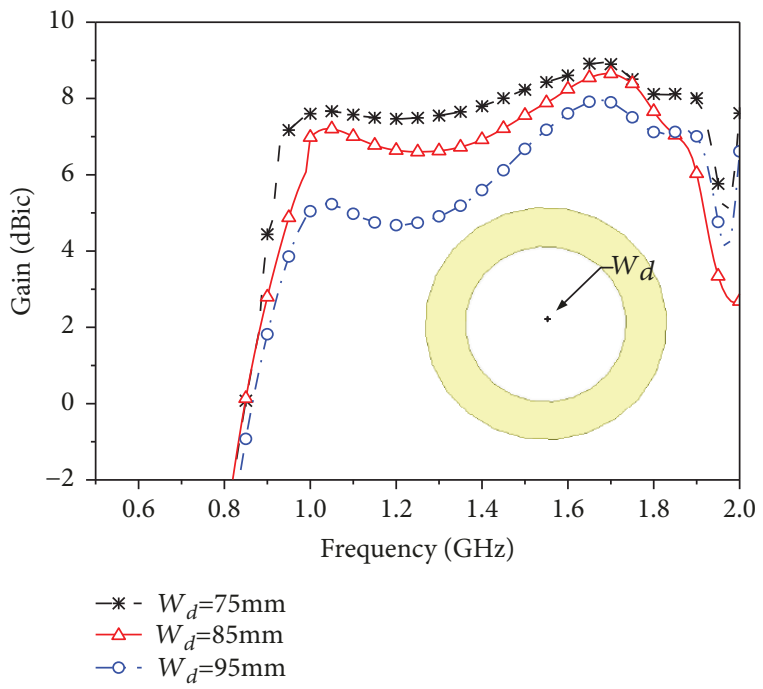

(a)

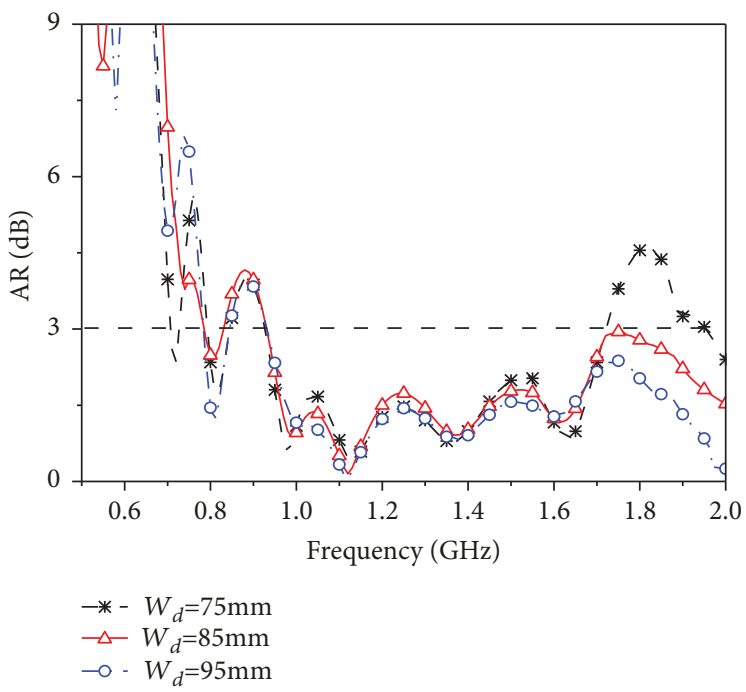

(b)

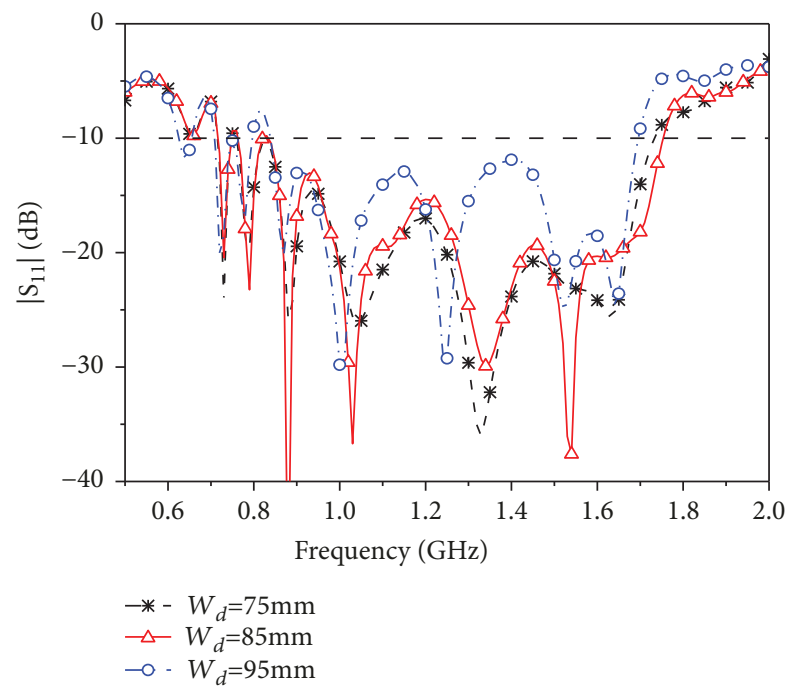

(c)

FIgURE 7: Effect of $W_{d}$ on the antenna. (a) Gains and (b) ARs at broadside direction. (c) $\left|S_{11}\right|$ s. 


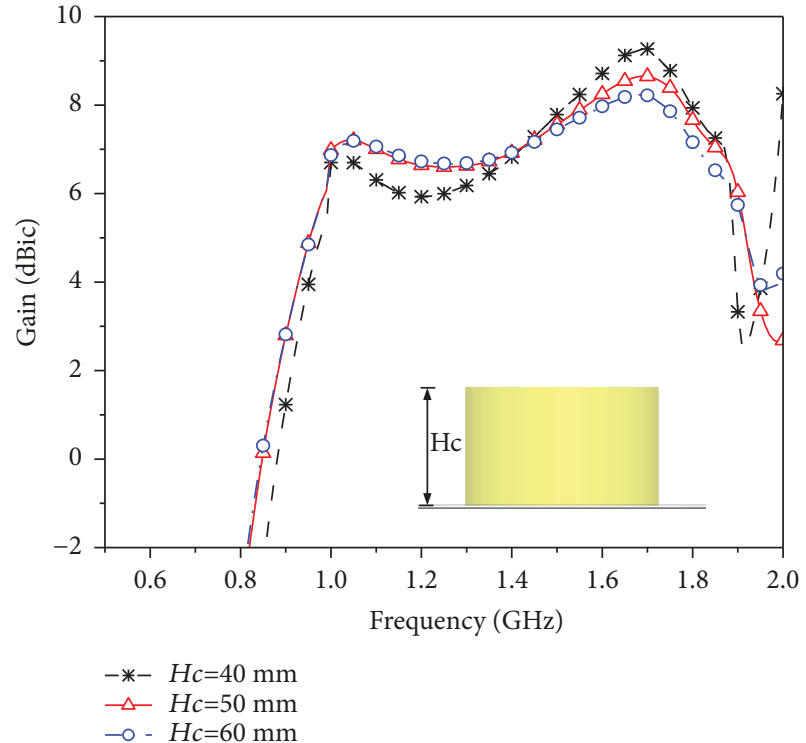

(a)

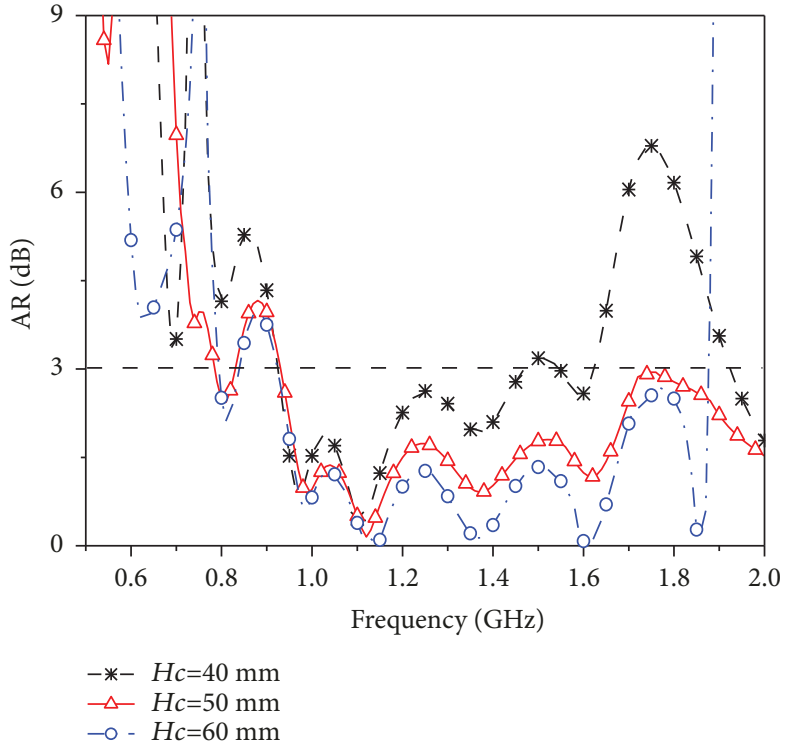

(b)

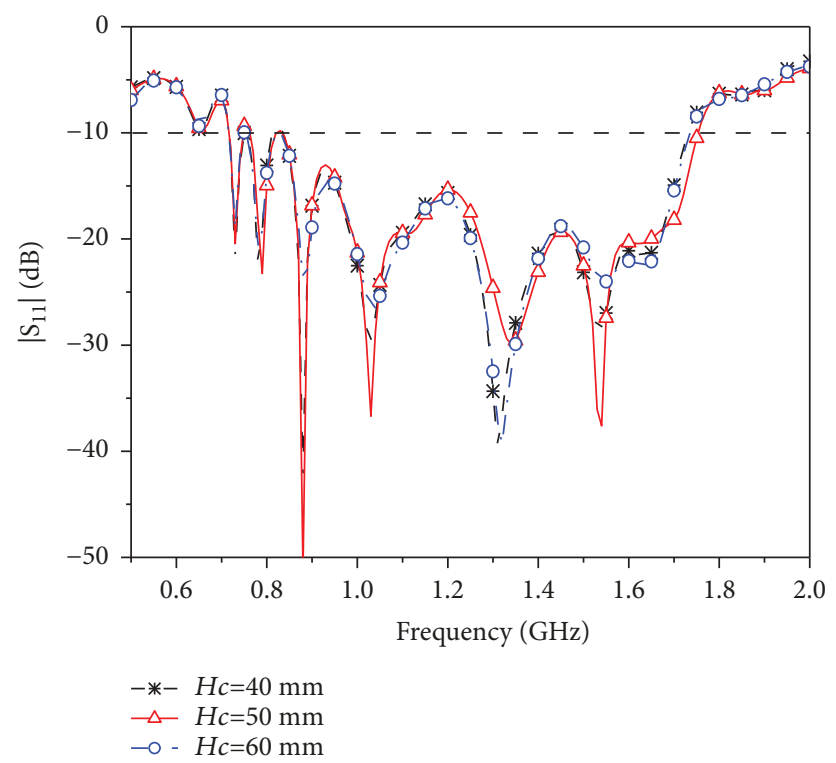

(c)

Figure 8: Effect of $H_{c}$ on the antenna. (a) Gains and (b) ARs at broadside direction. (c) $\left|S_{11}\right| s$.

$\mathrm{AR} \leq 3 \mathrm{~dB}$ of $76 \% \quad(0.78-1.78 \mathrm{GHz})$. As depicted in Figure 4(a), the gain at broadside direction of the ellipse dipoles without coupled frame is less than $6.00 \mathrm{dBic}$. Whereas, when a coupled frame is employed, the gain reaches $6.50 \mathrm{dBic}$. Furthermore, by adopting a loop cavity in Antenna 3, the gain of higher band is significantly raised to $8.75 \mathrm{dBic}$. In order to clearly understand the gain enhancement, the current distributions at $1.0 \mathrm{GHz}, 1.4 \mathrm{GHz}$, and $1.8 \mathrm{GHz}$ are given in Figure 5. The reason of gain enhancement is that the current for Antenna 3 is strong at the border of the ellipse dipoles and coupled frame. In other words, the electric field distributions and the effective radiation area are improved by the coupled frame. Meanwhile, the coupled current in the loop cavity improves the electric field distributions of the antenna. Thus, the effective radiation area is
TABLE 1: Parameters of antenna.

\begin{tabular}{lccccccc}
\hline Parameters & $L_{d}$ & $D_{p}$ & $L_{p}$ & $W_{p}$ & $H$ & $H_{c}$ & $D_{1}$ \\
Value $(\mathrm{mm})$ & 70 & 45 & 36 & 3 & 60 & 50 & 400 \\
Parameters & $D$ & $W_{d}$ & $W_{t}$ & $L_{t}$ & $W_{\mathrm{e}}$ & $L_{\mathrm{e}}$ & $L_{1}$ \\
Value $(\mathrm{mm})$ & 200 & 85 & 17.7 & 18 & 22.8 & 32 & 10 \\
Parameters & $L_{2}$ & $W_{1}$ & $W_{2}$ & $H_{c 1}$ & $W_{d 1}$ & $D_{a}$ & \\
Value $(\mathrm{mm})$ & 11.8 & 1.2 & 6 & 48 & 170 & 135 & \\
\hline
\end{tabular}

further increased. As shown in Figure 6, the major currentdensity distribution is on the ellipse dipoles and coupled frame, which means the dipoles and coupled frame are the 


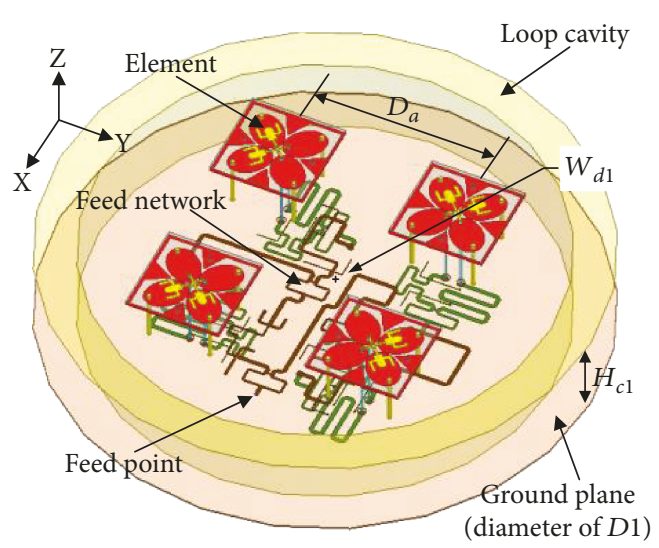

(a)

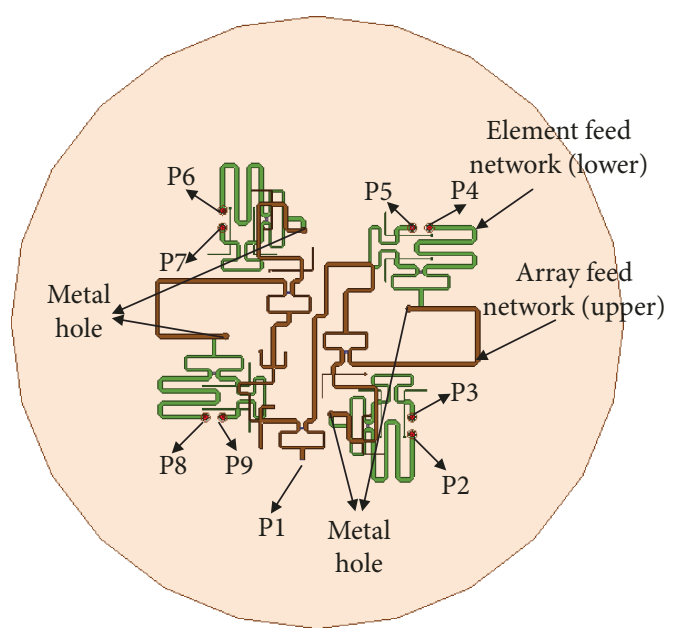

(b)

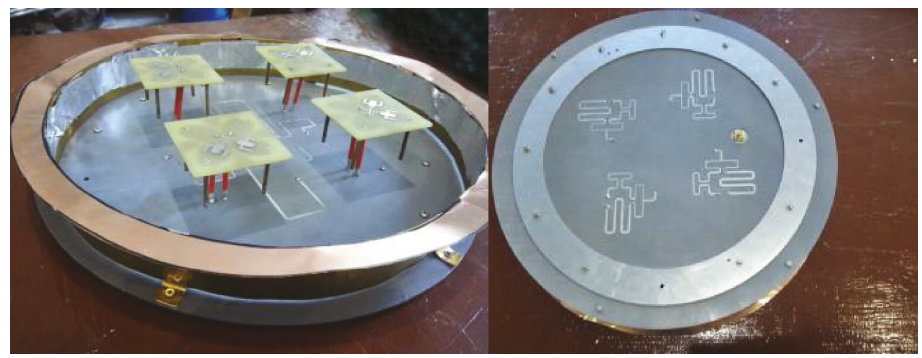

(c)

FIgure 9: Configuration of the proposed antenna array. (a) 3D view. (b) Feed network. (c) Photograph.

main radiators. Moreover, the main current-direction of time-dependent rotating are clearly observed, which confirm the RHCP radiation of the proposed antenna. With the improved effective radiation area, the gain of proposed antenna is dramatically improved. From Figures 4(b) and $4(c)$, the additional structures have a slight effect on $\left|S_{11}\right|$ and reduce $\mathrm{AR}$ at broadside direction of higher band. Therefore, such a desired antenna with better CP performance and high gain is obtained.

2.3. Parametric Studies. In order to deeply investigate the proposed antenna, two key parameters of the loop cavity are studied. Figure 7 shows the effect of width $W_{d}$ on antenna performance. At the same time, the result curves of $W_{d}=$ $75 \mathrm{~mm}, W_{d}=85 \mathrm{~mm}$, and $W_{d}=95 \mathrm{~mm}$ are labeled in black, red, and blue color, respectively. It is observed that impedance match at the middle band is deteriorating, and the side bands are stable with $W_{d}$ increases. In the meantime, the gain is imperatively augmented at the lower band. Ideally, $W_{d}$ should be as small as possible. However, as $W_{d}$ changes from $95 \mathrm{~mm}$ to $75 \mathrm{~mm}$, the higher band AR shows worse trend. So a good balance among impedance match, AR, and gain should be struck, and $W_{d}=85 \mathrm{~mm}$ is suitable and favorable. The other key factor is the height $H_{c}$. Figure 8 gives the gains, ARs at broadside direction, and $\left|\mathrm{S}_{11}\right| \mathrm{s}$ curves of proposed antenna with different width $H_{c}$, which varies from $40 \mathrm{~mm}$ to $60 \mathrm{~mm}$. In the meantime, the result curves of $H_{c}=40 \mathrm{~mm}$, $H_{c}=50 \mathrm{~mm}$, and $H_{c}=60 \mathrm{~mm}$ are marked in black, red, and blue color, respectively. From Figure $8, H_{c}$ impacts the gain and AR evidently, and the $\left|S_{11}\right|$ keeps stable. The higher band $\mathrm{AR}$ and lower band gain curves give better response, while $H_{c}$ becomes larger, whereas the higher band gain decreases. When $H_{c}=50 \mathrm{~mm}$, the better AR and gain during the whole operating band are achieved.

According to the above parametric studies, it can be summarized that the loop cavity makes a slight effect on the impedance match. On the contrary, AR and gain are very sensitive to the parameters of the loop cavity. Therefore, the crucial factors of this antenna are the parameters of the loop cavity. The final optimized parameters of the proposed antenna element are listed in Table 1.

\section{Wideband Antenna Array}

3.1. Configuration of Array. The configuration of the $2 \times 2 \mathrm{CP}$ sequentially rotated ellipse dipole array and the WPSFN are shown in Figure 9. Wideband antenna elements are spaced at $D_{a}$ (approximately $0.6 \lambda$ ), and they are placed on the ground plane with a diameter of $D_{1}$. Meanwhile, the SRT is adopted to the array to increase the AR property. In other words, each element is sequentially rotated with the same rotation of polarization and excited with a $90^{\circ}$ difference in phase.

As displayed in Figure 9(b), the array antenna is fed by a WPSFN, which consists of the element and array feed network. These two feed networks are etched on two PCB 


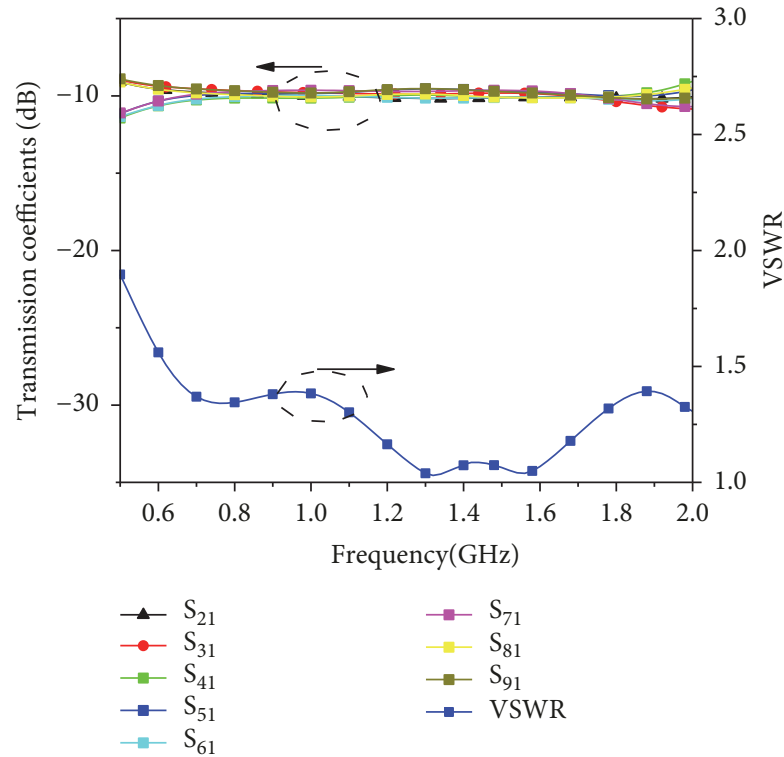

(a)

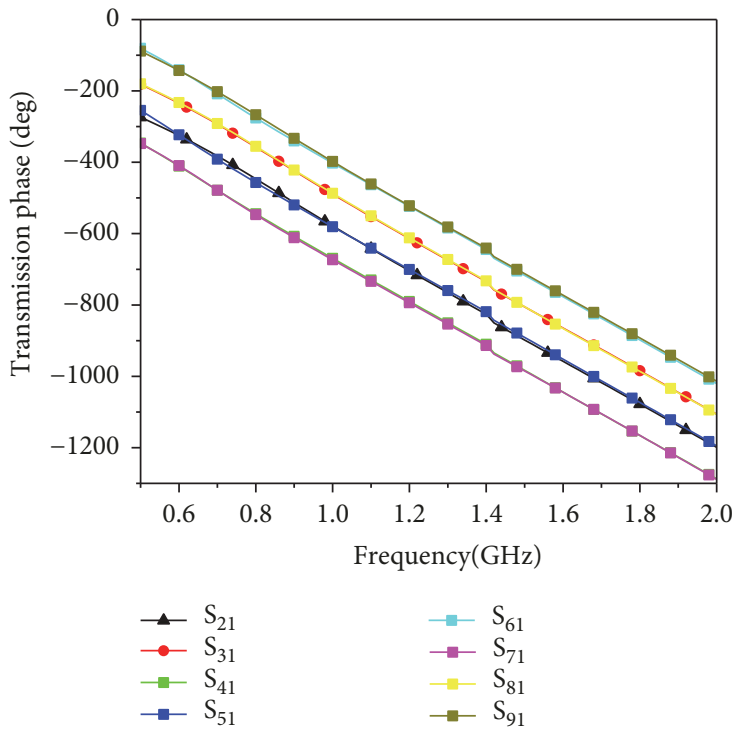

(b)

Figure 10: Performance of array feed network. (a) Transmission coefficients and VSWR. (b) Transmission phases.

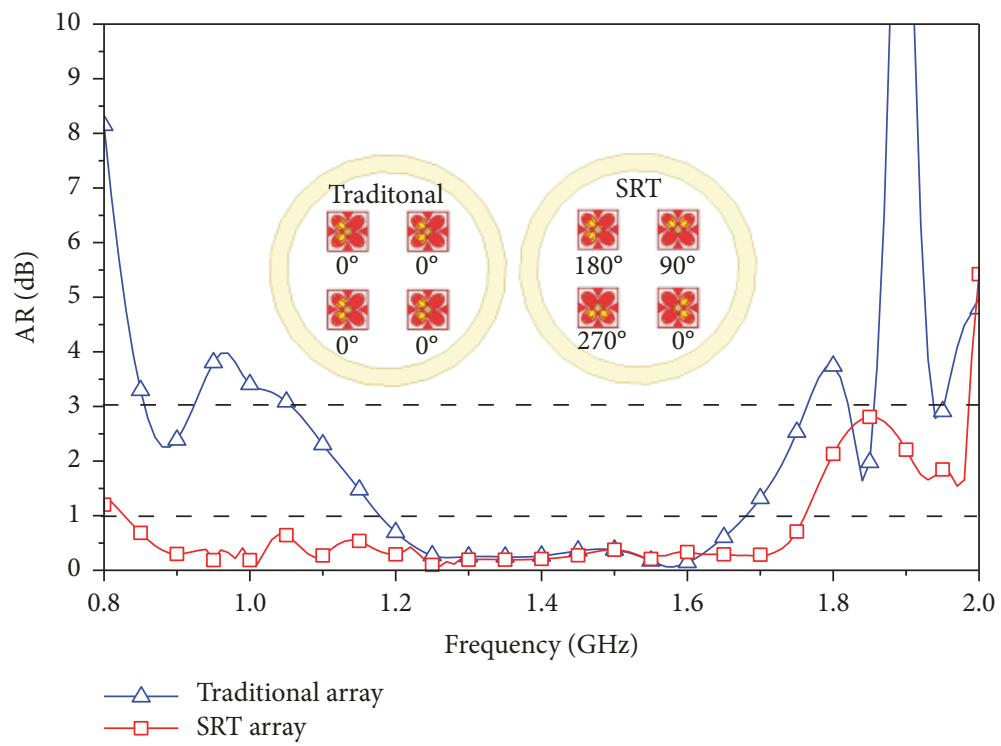

FIGURE 11: Simulated ARs at broadside direction of the traditional and the SRT array.

( $1 \mathrm{~mm}$ thick, $\left.\varepsilon_{\mathrm{r}}=2.65\right)$ and connected through metal holes in the PCBs. The element feed network is etched on the bottom side of the lower feed network PCB, while the array feed network is on the top side of the upper feed network PCB. In the meantime, the ground plane is printed on the bottom side of the upper PCB as a reflector. As shown in Figure 10, the simulated results illustrate that the operating band of $0.6-2.0 \mathrm{GHz}$ for VSWR $\leq 1.50$ is obtained. During the desired band, the good transmission coefficients and phases maintain an equal amplitude and $90^{\circ}$ difference in phase of each port. Based on the excellent performance of the network, the antenna array could show stable radiation and impedance characters among a wideband.
3.2. Array Analysis and Discussion. The comparison of ARs between traditional and SRT array is depicted in Figure 11. By utilizing the SRT, the $3 \mathrm{~dB}$ ARBW and AR performance are substantially enhanced. The red curve shows that the SRT array achieves $1 \mathrm{~dB}$ ARBW of $74.4 \%(0.81-1.77 \mathrm{GHz})$, while the blue curve reveals that the traditional array shows a poor $1 \mathrm{~dB}$ ARBW ranging from $1.20 \mathrm{GHz}$ to $1.68 \mathrm{GHz}$. Thus, the results demonstrate that the SRT has a good effect on the AR performance. From the discussions in Section 2, it is learned that the loop cavity plays a crucial role in the gain enhancement. Hence, this technique could be utilized in the $2 \times 2$ array. As shown in Figure 12, the peak gain of proposed antenna array without loop cavity is less than $12.8 \mathrm{dBic}$, and 


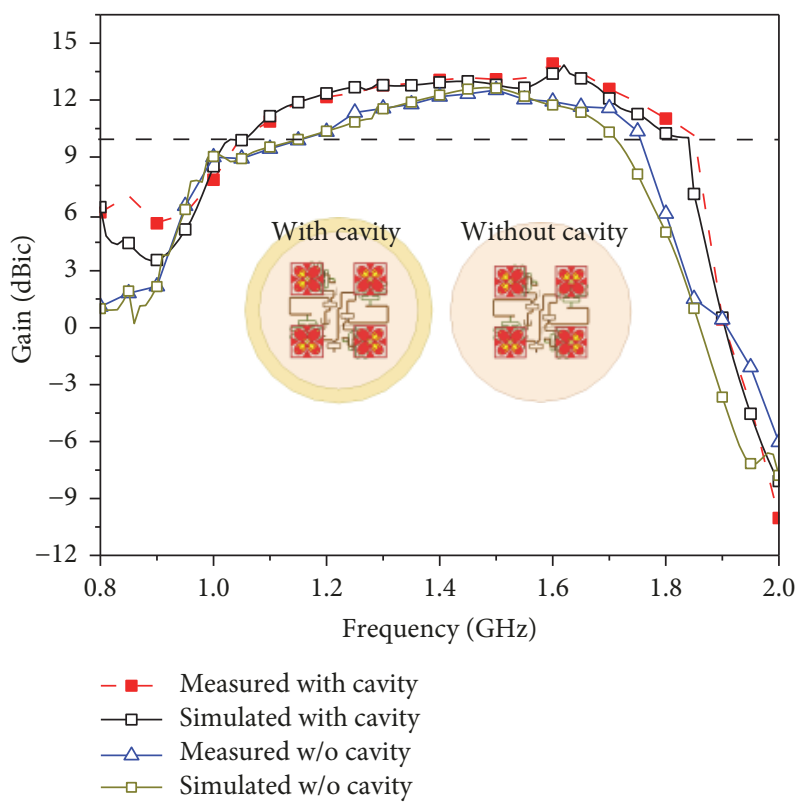

(a)

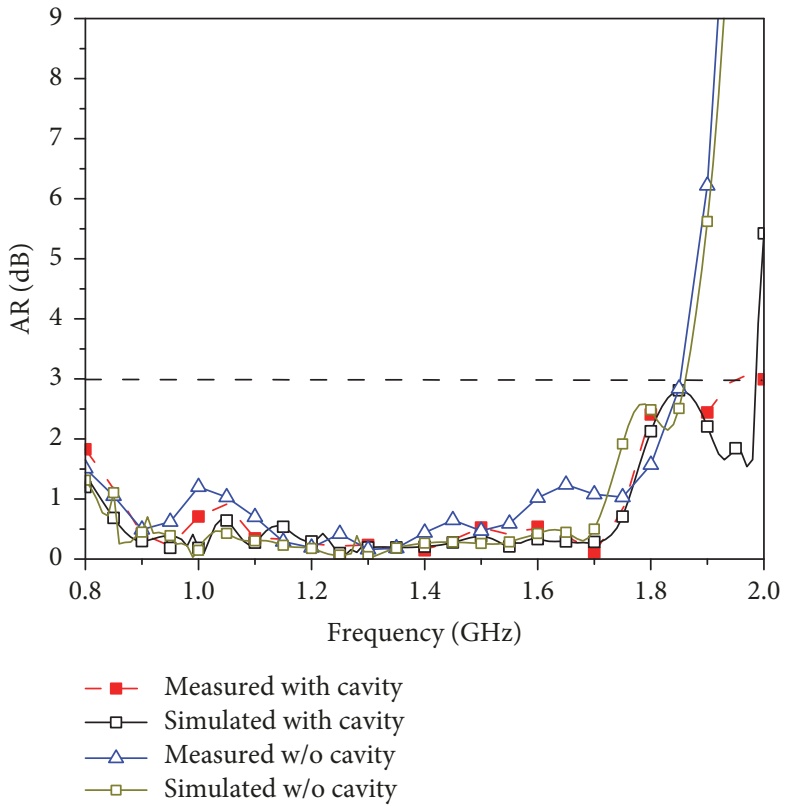

(b)

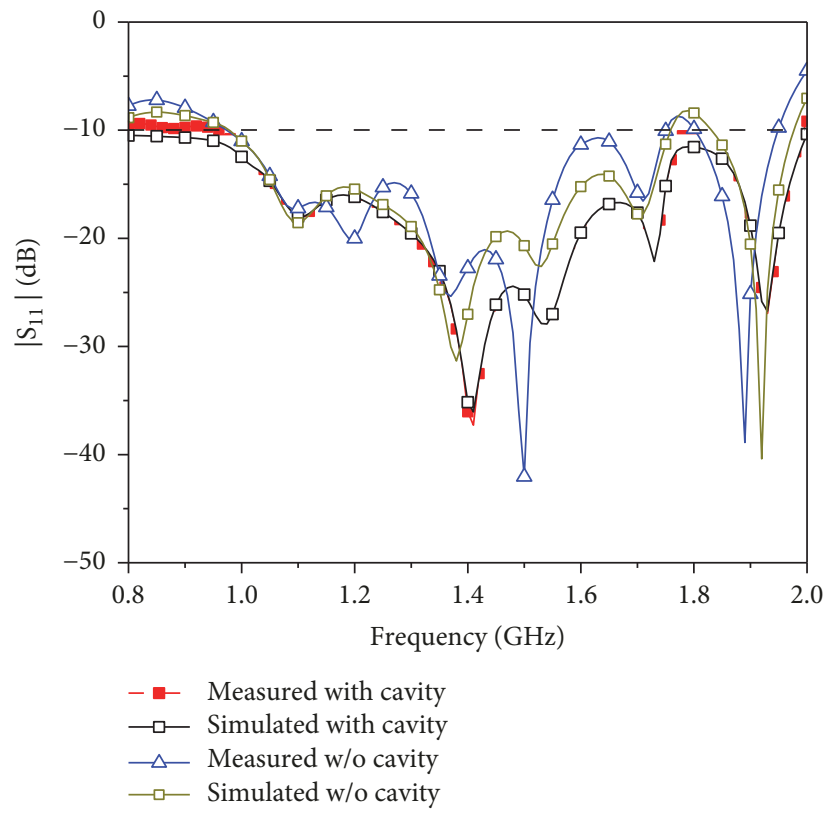

(c)

Figure 12: Measured and simulated gains, ARs at broadside direction, and $\left|S_{11}\right|$ s. (a) Gains. (b) ARs. (c) $\left|S_{11}\right|$ s.

the band width for gain $\geq 10 \mathrm{dBic}$ achieves $35.6 \%$ (1.20$1.72 \mathrm{GHz}$ ). By employing a loop cavity, the peak gain of $13.91 \mathrm{dBic}$ and the band width of $55.2 \%(1.05-1.85 \mathrm{GHz})$ for gain $\geq 10 \mathrm{dBic}$ are obtained, respectively. In the meantime, the $\left|S_{11}\right| s$ keep stable and AR shows better response at higher band, which shows a same trend with the discussion in Section 2.

\section{Experimental Results and Discussion}

The wideband CP antenna array is simulated, fabricated, and measured. The geometric optimized parameters are summarized in Table 1, and the photograph of the fabricated antenna is depicted in Figure 9(c). The measurements are carried out by using a network analyser Agilent E8363B and an anechoic chamber.

In Figure 12, the red and black curves give the measured and simulated results of the antenna with cavity, while the blue and yellow curves depict the measured and simulated results of the antenna without cavity. Figure 12(c) shows the simulated and measured $\left|S_{11}\right| s$ for the proposed antenna. It is found that $\left|\mathrm{S}_{11}\right| \leq-10 \mathrm{~dB}$ is about $85.7 \%(0.80-2.00 \mathrm{GHz})$. In the overlapped bandwidth of $\left|\mathrm{S}_{11}\right| \leq-10 \mathrm{~dB}$, the $\mathrm{AR}$ at broadside direction keeps blow 

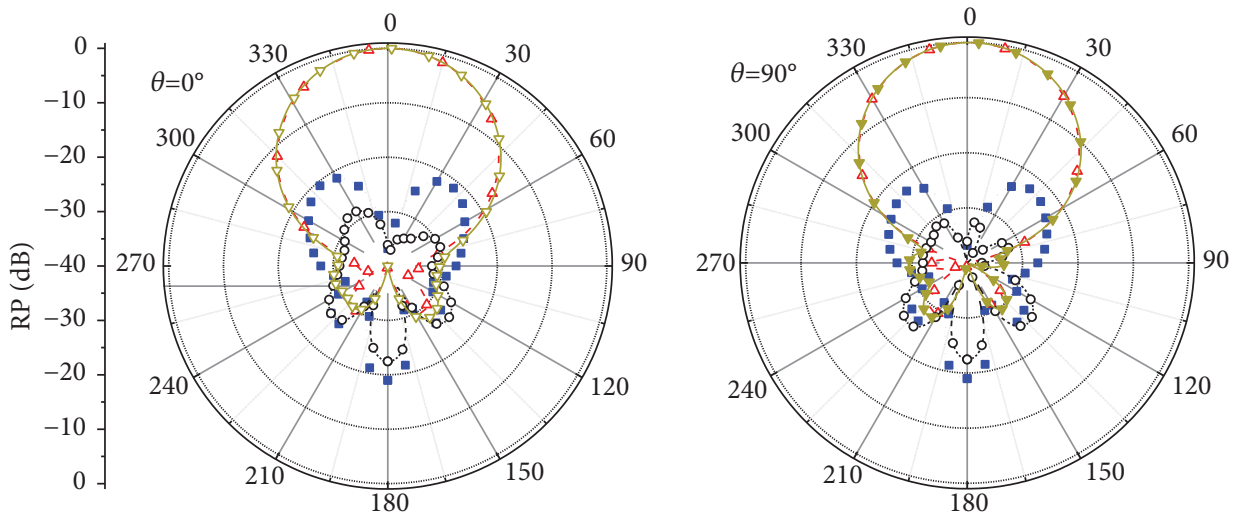

-. Measured LHCP

- $\triangle$. Measured RHCP

$\multimap$ Simulated LHCP

$\neg$ Simulated RHCP

(a)
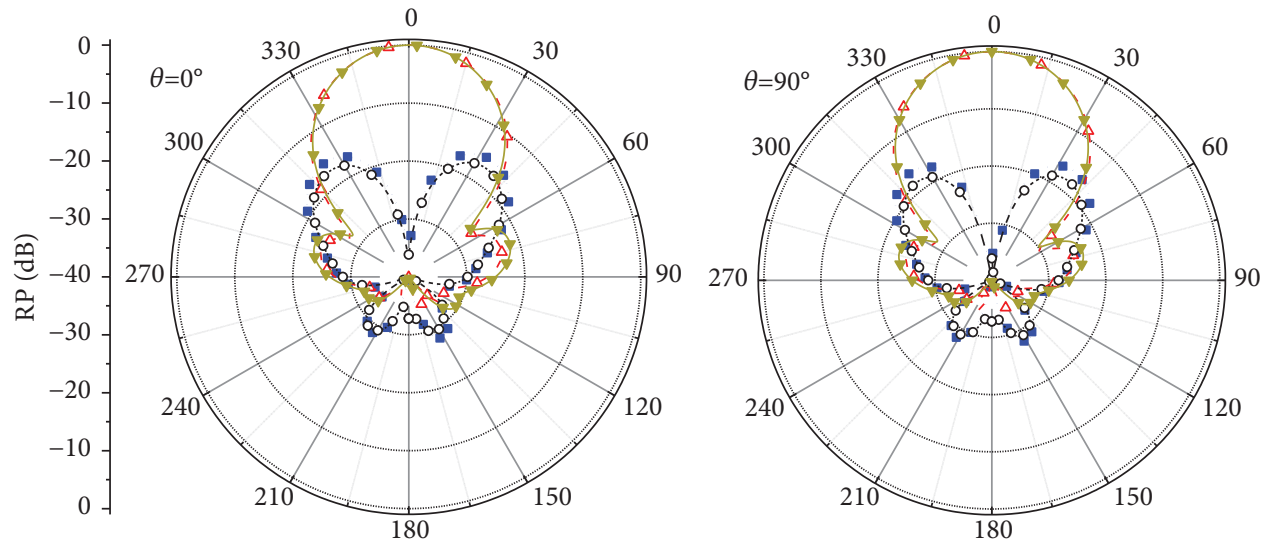

-. Measured LHCP

- $\triangle$. Measured RHCP

$\rightarrow$ Simulated LHCP

$\rightarrow$ Simulated RHCP

(b)
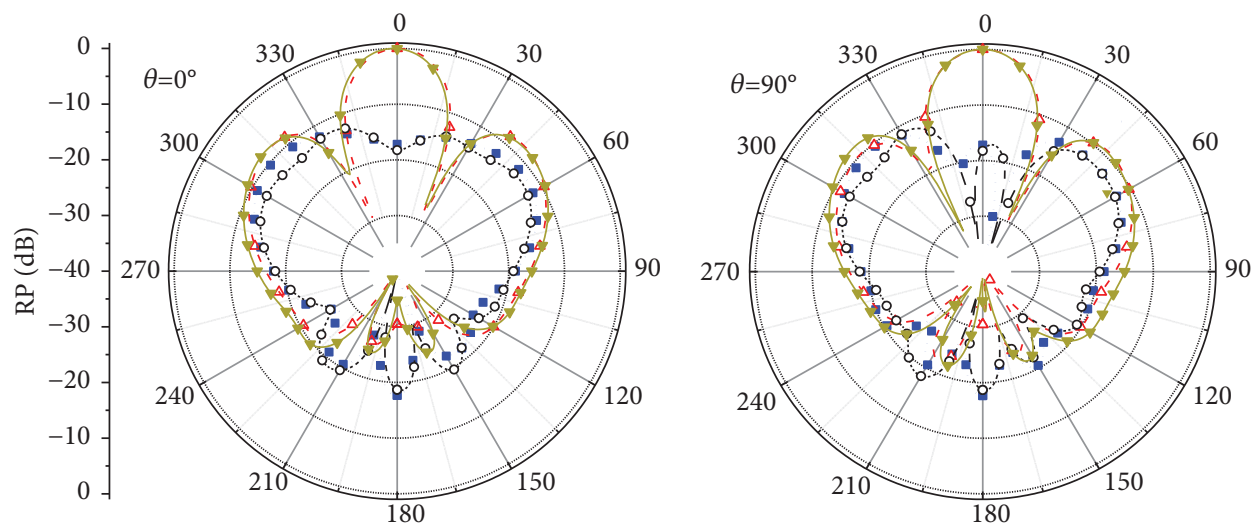

-. Measured LHCP

$-\triangle$. Measured RHCP

$\multimap$ Simulated LHCP

$\rightarrow$ Simulated RHCP

(c)

FIGURE 13: Measured and simulated radiation patterns (RPs) at (a) $1.05 \mathrm{GHz}$, (b) $1.45 \mathrm{GHz}$, and (c) $1.85 \mathrm{GHz}$. 
TABLE 2: Performance summary of published $2 \times 2$ arrays and the proposed work.

\begin{tabular}{lcccc}
\hline Ref. & {$[17]$} & {$[19]$} & This work \\
Dimension & $1.21 \lambda_{0} \times 1.21 \lambda_{0} \times 0.027 \lambda_{0}$ & $0.42 \lambda_{0} \times 0.42 \lambda_{0} \times 0.064 \lambda_{0}$ & $0.68 \lambda_{0} \times 0.68 \lambda_{0} \times 0.03 \lambda_{0}$ & $2 \pi \times\left(0.41 \lambda_{0}\right)^{2} \times 0.24 \lambda_{0}$ \\
Peak gain (dBic) & 12.20 & 9.00 & 8.25 & 13.91 \\
IBW & $18 \%$ for $\left|\mathrm{S}_{11}\right| \leq-10 \mathrm{~dB}$ & $42.9 \%$ for VSWR $\leq 2$ & $29 \%$ for $\left|\mathrm{S}_{11}\right| \leq-10 \mathrm{~dB}$ & $85.7 \%$ for $\left|\mathrm{S}_{11}\right| \leq-10 \mathrm{~dB}$ \\
ARBW (AR $\leq 3 \mathrm{~dB})$ & $16 \%$ & $22.8 \%$ & $15.5 \%$ & $85.7 \%$ \\
\hline
\end{tabular}

$3 \mathrm{~dB}$ and the $1 \mathrm{~dB}$ ARBW reaches to $74.4 \%(0.85-1.78 \mathrm{GHz})$. In Figure 12(a), the result shows that the copolarization (RHCP) gain $\geq 10 \mathrm{dBic}$ is ranging from $1.05 \mathrm{GHz}$ to $1.85 \mathrm{GHz}$, and the peak gain of $13.91 \mathrm{dBic}$ is obtained at $1.6 \mathrm{GHz}$. The measured and simulated results of the normalized radiation patterns at $1.05 \mathrm{GHz}, 1.45 \mathrm{GHz}$, and $1.85 \mathrm{GHz}$ are displayed in Figure 13. The copolarization (RHCP) and cross-polarization (LHCP) radiation patterns (RPs) are obtained at XOZ-plane $\left(\theta=0^{\circ}\right)$ and YOZ-plane $\left(\theta=90^{\circ}\right)$. Consequently, all the simulated and measured results exhibit acceptable agreement.

Table 2 depicts comparisons between the proposed array and published $2 \times 2$ arrays in terms of peak gain, dimension, IBW, and ARBW. It can be easily seen that the proposed array has a perfect wideband CP performance, wide impedance bandwidth, and high gain at the same time.

\section{Conclusion}

In this paper, a wideband CP antenna element and array with gain enhancement are proposed. The antenna element introduces a wideband ellipse dipole, a harpoon-shaped feed patch, and a coupled frame to obtain wideband IBW and ARBW. Due to the coupled frame, the peak gain of element is increased from $0.5 \mathrm{dBic}$ to $6.2 \mathrm{dBic}$. Furthermore, a loop cavity is drawn into the antenna element to increase the peak gain to $8.75 \mathrm{dBic}$ significantly. Then, a $2 \times 2 \mathrm{CP}$ sequentially rotated ellipse dipole array is investigated. By employing the SRT, the proposed array shows a perfect AR performance. From the analysis of the loop cavity, a same technique is adopted to the array, while the peak gain reaches to $13.91 \mathrm{dBic}$ and the band width of $55.2 \%(1.05-1.85 \mathrm{GHz})$ for gain $\geq 10 \mathrm{dBic}$ are obtained. Finally, an array prototype is fabricated and tested. The results show acceptable agreement between simulation and testation. In brief, the proposed antenna exhibits a wideband CP property and high gain, which reveals that the proposed antenna could be a good choice for global navigation satellite system (GNSS).

\section{Data Availability}

The data used to support the findings of this study are available from the corresponding author upon request.

\section{Conflicts of Interest}

The authors declare that there is no conflict of interests regarding the publication of this paper.

\section{Funding}

This work was supported by the National Natural Science Foundation of China no. 61601351.

\section{References}

[1] H. Jiang, Z. Xue, W. Li, and W. Ren, "Broad beamwidth stacked patch antenna with wide circularly polarised bandwidth," Electronics Letters, vol. 51, no. 1, pp. 10-12, 2015.

[2] H. Oraizi and R. Pazoki, "Wideband circularly polarized aperture-fed rotated stacked patch antenna," IEEE Transactions on Antennas and Propagation, vol. 61, no. 3, pp. 10481054, 2013.

[3] M. Zou and J. Pan, "Wide dual-band circularly polarized stacked rectangular dielectric resonator antenna," IEEE Antennas and Wireless Propagation Letters, vol. 15, pp. 11401143, 2015.

[4] L. Li, Y. Zhang, J. Wang, W. Zhao, S. Liu, and R. Xu, "Bandwidth and gain enhancement of patch antenna with stacked parasitic strips based on LTCC technology," International Journal of Antennas and Propagation, vol. 2014, Article ID 461423, 5 pages, 2014.

[5] A. Altaf, Y. Yang, K.-Y. Lee, and K. C. Hwang, "Wideband circularly polarized spidron fractal slot antenna with an embedded patch," International Journal of Antennas and Propagation, vol. 2017, Article ID 3595620, 7 pages, 2017.

[6] M. S. Ghaffarian, G. Moradi, and P. Mousavi, "Wide-band circularly polarized slot antenna by using novel feeding structure," in 2017 11th European Conference on Antennas and Propagation (EUCAP), Paris, France, March 2017.

[7] L. Ge, C.-Y.-D. Sim, H.-L. Su, J.-Y. Lu, and C. Ku, "Single-layer dual-broadband circularly polarised annular-slot antenna for WLAN applications," IET Microwaves, Antennas \& Propagation, vol. 12, no. 1, pp. 99-107, 2017.

[8] C. Xue, H. Wang, X. Jiang, and Y. Huang, "A single-feed arrow-shaped circularly polarized antenna with unbalanced slotted artificial magnetic conductor for GNSS application," in 2016 IEEE MTT-S International Microwave Workshop Series on Advanced Materials and Processes for $\mathrm{RF}$ and $\mathrm{THz}$ Applications (IMWS-AMP), Chengdu, China, July 2016.

[9] W. Yang, Y. Pan, S. Zheng, and P. Hu, "A low-profile wideband circularly polarized crossed-dipole antenna," IEEE Antennas and Wireless Propagation Letters, vol. 16, pp. 2126-2129, 2017.

[10] Y. He, W. He, and H. Wong, "A wideband circularly polarized cross-dipole antenna," IEEE Antennas and Wireless Propagation Letters, vol. 13, pp. 67-70, 2014.

[11] W. J. Yang, Y. M. Pan, and S. Y. Zheng, "A low-profile wideband circularly polarized crossed-dipole antenna with wide axial-ratio and gain beamwidths," IEEE Transactions on Antennas and Propagation, vol. 66, no. 7, pp. 3346-3353, 2018. 
[12] H. H. Tran, I. Park, and T. K. Nguyen, "Circularly polarized bandwidth-enhanced crossed dipole antenna with a simple single parasitic element," IEEE Antennas and Wireless Propagation Letters, vol. 16, pp. 1776-1779, 2017.

[13] T. K. Nguyen, H. H. Tran, and N. Nguyen-Trong, "A wideband dual-cavity-backed circularly polarized crossed dipole antenna," IEEE Antennas and Wireless Propagation Letters, vol. 16, pp. 3135-3138, 2017.

[14] B. Feng, W. Hong, S. Li, W. An, and S. Yin, "A dual-wideband double-layer magnetoelectric dipole antenna with a modified horned reflector for 2G/3G/LTE applications," International Journal of Antennas and Propagation, vol. 2013, Article ID 509589, 9 pages, 2013.

[15] T. K. Nguyen and I. Park, "Design of a substrate-integrated Fabry-Pérot cavity antenna for $K$-band applications," International Journal of Antennas and Propagation, vol. 2015, Article ID 373801, 12 pages, 2015.

[16] H. Boutayeb and M. Nedil, "High gain slot array with FabryPerot cavity feeding circuit," International Journal of Antennas and Propagation, vol. 2016, Article ID 9674742, 5 pages, 2016.

[17] T. Zhang, W. Hong, and K. Wu, "Analysis and optimum design of sequential-rotation array for gain bandwidth enhancement," IEEE Transactions on Antennas and Propagation, vol. 63, no. 1, pp. 142-150, 2015.

[18] Y.-J. Hu, W.-P. Ding, and W.-Q. Cao, "Broadband circularly polarized microstrip antenna array using sequentially rotated technique," IEEE Antennas and Wireless Propagation Letters, vol. 10, pp. 1358-1361, 2011.

[19] X. Chen, L. Wang, D. Wu, J. Lei, and G. Fu, "Compact and wideband directional circularly polarized distributed patch antenna with high efficiency," IEEE Access, vol. 5, pp. 15942 15947, 2017.

[20] J. Pourahmadazar and V. Rafii, "Broadband circularly polarised slot antenna array for L- and S-band applications," Electronics Letters, vol. 48, no. 10, p. 542, 2012.

[21] S. Maddio, "A compact wideband circularly polarized antenna array for C-band applications," IEEE Antennas and Wireless Propagation Letters, vol. 14, pp. 1081-1084, 2015.

[22] S.-Y. Eom and H.-K. Park, "New switched-network phase shifter with broadband characteristics," Microwave and Optical Technology Letters, vol. 38, no. 4, pp. 255-257, 2003. 


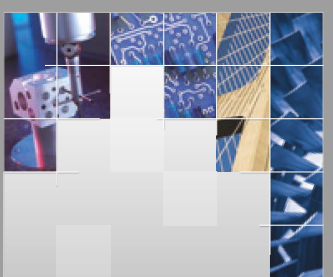

\section{Enfincering}
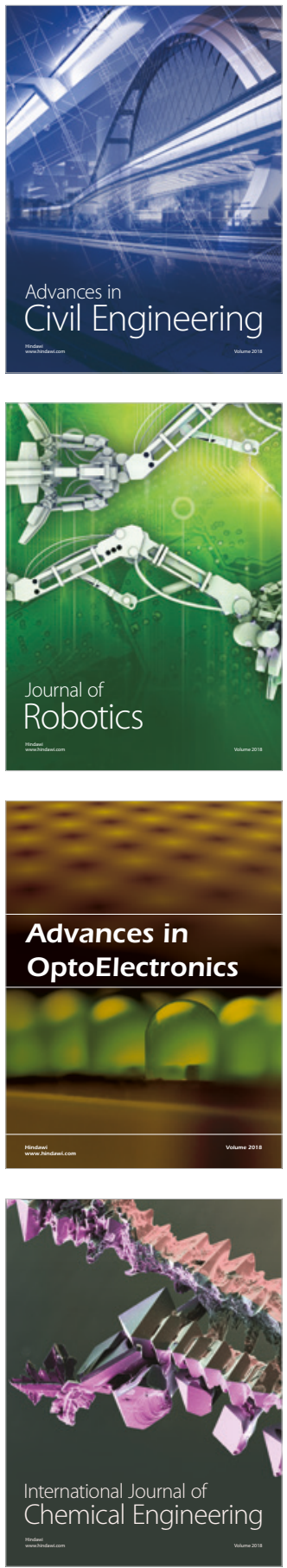

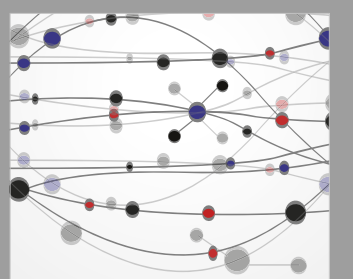

\section{Rotating \\ Machinery}

The Scientific World Journal

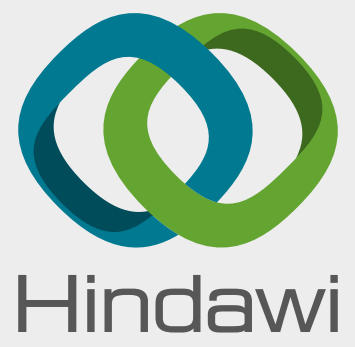

Submit your manuscripts at

www.hindawi.com
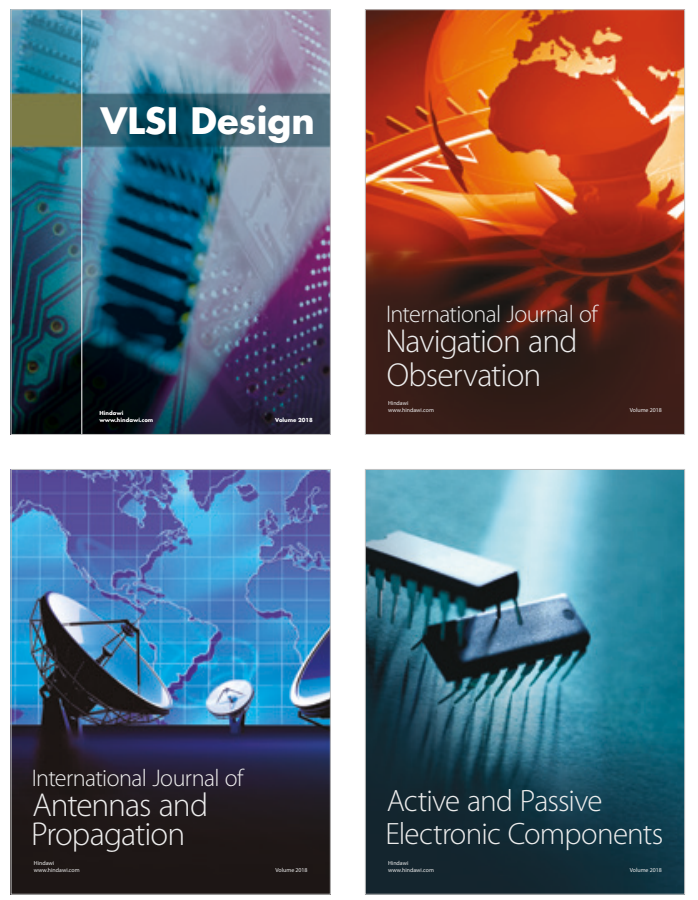
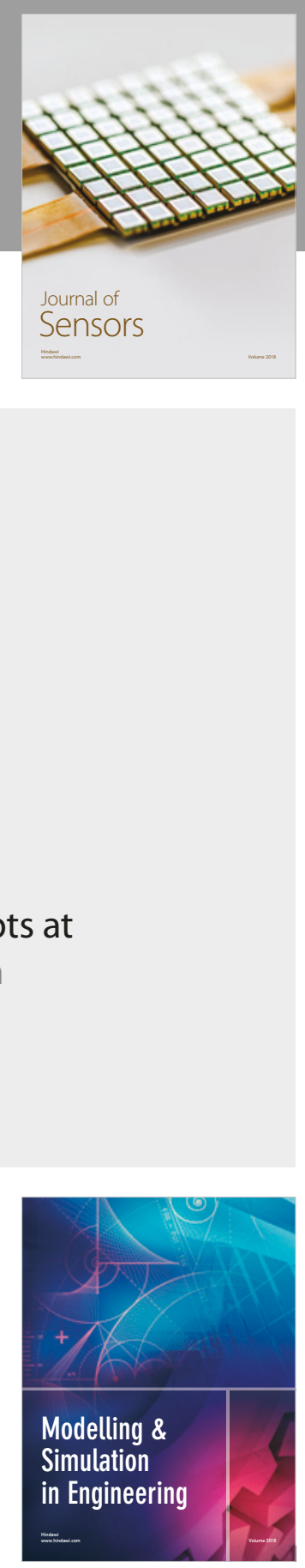

\section{Advances \\ Multimedia}
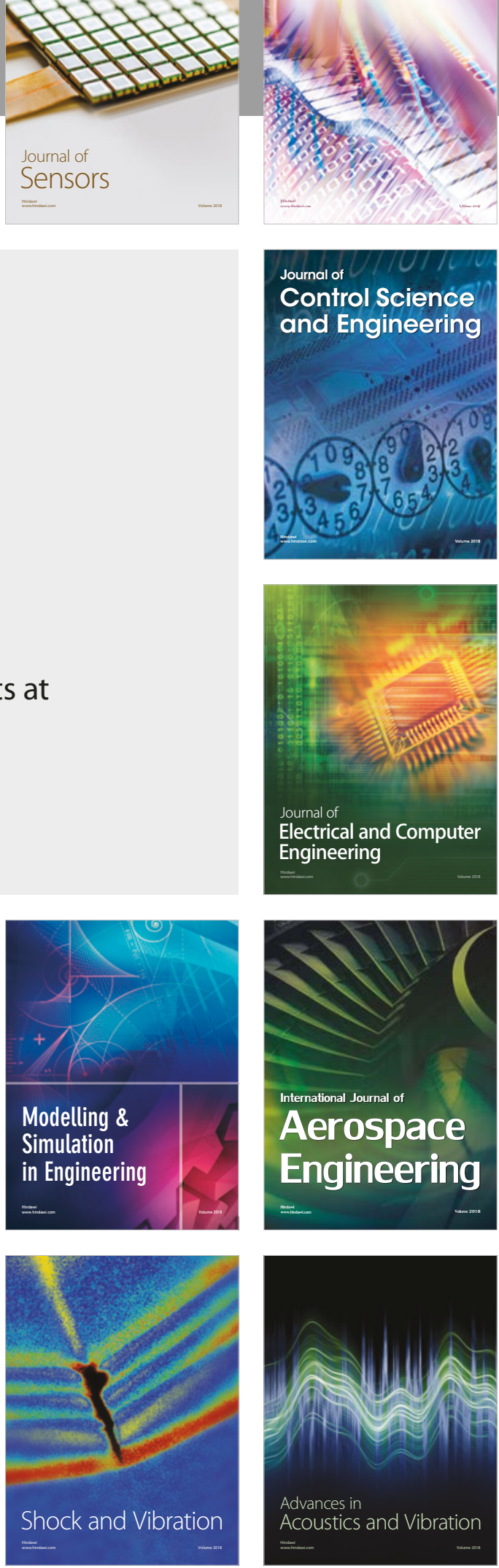